\title{
Diversity education at land-grant universities from the perspective of a female student of color
}

COMMENTARY ON RACE AND ETHNICITY IN FOOD SYSTEMS

\author{
Olivia A. Peña* \\ University of Vermont
}

Submitted June 17, 2015 / Published online August 28, 2015

Citation: Peña, O. A. (2015). Diversity education at land-grant universities from the perspective of a female student of color. Journal of Agriculture, Food Systems, and Community

Development, 5(4), 121-124. http://dx.doi.org/10.5304/jafscd.2015.054.020

Copyright (C) 2015 by New Leaf Associates, Inc.

\begin{abstract}
As a land-grant university student, in order to graduate I must fulfill the requirement of a twopart diversity course. In reflecting on my own experience and growth from taking these classes as a female student of color, I examined my involvement within the agrifood system. I assert the need for diversity education and training in land-grant universities. Finally, I state the necessity for increased practices and strategies for land grants and extension departments to recruit and retain more diverse students, staff, and faculty.
\end{abstract}

\section{Keywords}

barriers, diversity, education, extension, land-grant universities, people of color, race, requirements, students

\footnotetext{
* Olivia A. Peña, Department of Animal and Veterinary Sciences; Terrill Hall; University of Vermont, Burlington, Vermont 05405 USA; +1-802-656-2070; opena@,uvm.edu
}

\section{Introduction}

When I tell individuals, friends, and family from my small suburban hometown about my interest in sustainable food systems and my studies in agricultural sciences and development, I frequently receive astonished responses due to my nonfarming background. "Why agriculture?" I am often asked, to which I respond by explaining our shared connection to food and the ways in which production, distribution, and consumption methods affect our entire society. Finally, I explain that, despite my not-so-agrarian background, I am able to study sustainable agriculture due to the Morrill Acts' creation of land-grant institutions, and to the Smith-Lever Act (1914), which allocates federal support and funding annually to each state to enhance the study and research of agriculture and other applied fields, and also created and funds extension services to share the advancements and resources with American citizens.

Attending a land-grant university in the 
Northeast has given me the opportunity to connect with other students who have similar interests yet hail from different locations and backgrounds. My involvement with agriculture began as a young equestrian in my suburban neighborhood. Wishing to further pursue my interest in large animals and livestock, I applied and enrolled in a land-grant university as an animal science major. As my education progressed, I learned more about our modern food system and its impacts on our health, society, economy, and environment. By declaring double minors in nutrition and food science, and food systems, I have been able to supplement my major with transdisciplinary subjects.

As a female student of color in the College of Agriculture and Life Sciences at an institution where more than 83 percent of students identify as primarily white, I often reflect on $m y$ current and future involvement in the agrifood system as compared to that of my peers and classmates. While some of my peers are eager to get their hands dirty working on local organic farms during the summer or picking up a part-time job at a nearby dairy after classes, I am hesitant to get involved in the production aspect because of my perceptions of the past and present relationships of minorities and farm labor.

In this commentary, I will examine my own personal barriers in agricultural education and within the agrifood system. Through this lens, I will explain the need and purpose for diversity education and training at land-grant universities. Finally, I will assert the necessity for increased practices and strategies for land grants and extension departments in the recruitment and retention of a more diverse faculty, staff, and student body.

\section{Diversity Training and Education}

Of the U.S.'s 70 land-grant universities, 43 have instituted diversity requirements for their undergraduate core curriculum (Association of Public and Land-grant Universities [APLU], 2012). In many cases, diversity course requirements are embedded in the curriculum in order for students to, as Cornell University typifies, "enhance their abilities to communicate with people of different cultural perspectives; to listen carefully and respectfully to the views of others, especially views with which they disagree; and to employ ethical reasoning in judging ideas, actions, and their implications" (Cornell University, College of Agriculture and Life Sciences, n.d., para. 1). To meet the growing diverse population of our nation and more specifically the increase of students of color enrolling in colleges and universities, more institutions are instating this requirement into their general education core curriculum.

However, these requirements may vary in their specificity. For example, some universities, such as Clemson and Washington State, have a rather broad three-credit course requirement with the goal for students to "demonstrate the ability to critically compare and contrast world cultures in historical and/or contemporary contexts" (Clemson University, 2014, p. 37) or "understand, respect and interact constructively with others of similar and diverse cultures, values, and perspectives" (Washington State University, 2014, p. 41). These requirements can be met through certain classes that may cover domestic or global cultures. Allowing for overly flexible diversity coursework may mask the initial purpose and mission of the requirement. While focusing on global diversity allows for broader perspectives of the world beyond our country, this can lead to obliviousness to the perspectives and issues that exist between white and minority identities in the U.S.

Some land-grant universities and institutions established by the acts of 1862 and 1890 have more specific requirements that address the issue of race and racism within the United States. North Carolina State University has a three-credit diversity requirement, with the reasoning that "the study of diversity in the United States provides students the opportunity to consider questions of difference and culture, identity and community, privilege and oppression, and power and responsibility in our nation, and to gain an understanding of how these issues affect both individuals and communities" (North Carolina State University, 2014, p. 150). General diversity courses that meet the requirement, such as an English course that explores African American literature, can be used to portray an African American perspective. However, in a land-grant setting offering more diversity courses in agriculture could have a 
powerful effect in following the mission of land grants: to be able to successfully offer agricultural and technical advancements to a diverse range of American citizens.

At my university, the diversity requirement is comparably particular, with required classes that critically assess race and racism in the U.S. context. The diversity class in which I was enrolled was a societal and developmental analysis of our modern food system and the historical background that led to its current structure. In my research on domestic diversity courses across the country, few land-grant universities offered courses in relation to agriculture.

By viewing the food system in the context of its social component, my entire outlook on agriculture and my intentions for using my education were altered. Previously I had been very focused on the environmental and economic effects of conventional and mainstream agriculture. Understanding that the causes and origins of socially constructed racism stemmed from agriculture was shocking to me. The creation of the constructs of race and racism to justify the involvement of subordinate identities - more specifically ethnic minorities - in early U.S. agricultural production systems has led to the overpowering effects of systemic race and racism in a society that is certainly not post-racial. These concepts were very groundbreaking and empowering for me.

\section{Implications of Diversity Education on Students of Color}

Despite learning about minority groups in the U.S. from a young age-from the original populations that inhabited this country, to plantation agriculture and slavery, to the Civil Rights Movement-it was not until this diversity course in my sophomore year of college that I learned about the systemic causes and modern day effects of racism, despite the strides that minorities have made in regards to civil rights. As an underrepresented agricultural student reflecting on my previous views of minorities and farming, my personal interpretation has been shaped by historically traditional tropes — subjugated Native Americans, enslaved Africans, liberated African Americans who still experienced trouble accessing land and resources, or exploited Latinos (Grant, Wood, \& Wright, 2012). The thought of following in these exact, or emblematically similar, footsteps had always deterred me from experiencing the joy and nobility of farm work that white peers and classmates often share. For example, a white peer asserts the privilege of jumping head-first into a position as a farmhand, working in the field with little hesitation, while I have found it challenging to take on a role that was and often still is passively held by other minorities. This led me to question how many other underrepresented students feel similar personal or systemic barriers to an agricultural education at a land-grant university, or a farming occupation, despite their strong interest.

In the required diversity courses offered at many land-grant institutions, a study in and reflection on a variety of contexts about diverse cultures and their perspectives and views are carried out. When students of color do not have access or even see individuals who are outwardly similar to them involved in an industry of interest such as agriculture, they often look to previous views and roles in agriculture that their predecessors may have taken. Students of color may, or may not, notice the privilege that whites assert within the food system-the ability and privilege to embrace any role, from a laborer to a farm operator, or even as a CEO of a multimillion-dollar food corporation-with comparably less personal barriers. While reflecting on the history and even present systemic tribulations and subsequent oppressions that exist for individuals of color, students may feel the presence of a personal barrier simply due to the knowledge of such an existing element. However, these courses also have the opportunity to promote the empowerment of social and racial justice.

\section{Moving Forward and Steps for Extension and Outreach}

In reflecting on my personal barriers, I wonder about barriers that other individuals of color face when considering involvement in the agricultural field. Carolyn Finney (2006) discusses such barriers in "Black Faces, White Spaces: African Americans and the Great Outdoors," highlighting that some may feel that they are faced with "exclusionary practices." The second Morrill Act of 1890 was 
enacted 125 years ago. Since this time many strides have been made in advancing higher agricultural education Moving forward, I see even more potential for individuals of color to access education at land grants across the country. However, their inclusionary practices have room for improvement as well.

The reasoning behind diversity requirements at land-grant universities vary by the institution; however, each generally strives to educate and engage students in a reflection on the causes and effects of racism and race relations in our society. In my experience of learning about diversity in the domestic and global food systems contexts, my views of and barriers to agricultural production have changed. The academic agricultural community would benefit greatly by adding or increasing training and education on diversity within the food system.

In my reflection of my diversity coursework, I was curious about the structure and organization of diversity requirements at other land-grant universities. Although there is little detailed information and data on land-grant diversity requirements available, this little-explored area has great potential. I foresee great outcomes deriving from further examination and research on diversity training, education, and courses that relate directly to our domestic food systems. We must look inward at our own domestic issues and potential before we step outward to make change in global food systems. After my study and in-depth reflection on diversity within food systems, I have considered my barriers and realized that a better alternative is empowerment for action. After getting my bachelor of science degree, I hope to further my career in food systems in a graduate program. In pursuing higher education, I will get involved in extension programs to be able to serve underrepresented communities in rural settings. Eventually, I hope to have a career in public health and to contribute to a food system that is more sustainable-economically, socially, and environmentally.

Throughout my diversity courses, I was engaged in the class as an empowered learner. With the knowledge gained subsequently, I see myself taking the next steps as an empowered doer. In diversity courses offered by land-grant universities, an emphasis on empowerment and change will encourage white and minority students to examine both their own and others' personal barriers. Additionally, students of all races and identities can bring about change by understanding the gender and racial barriers that exist, and consequently contributing to a more diverse food system by getting involved, listening, and learning about diverse identities, and empowering themselves and others.

\section{Acknowledgements}

I would like to extend my endless appreciation for the help of Dr. Shoshannah Inwood and Dr. Jason Parker for their generous assistance and reviews in completing this commentary. A special thank you to Kelly and Alex Peña for their continued inspiration and endless support.

\section{References}

Association of Public and Land-grant Universities [APLU]. (2012). The land-grant tradition. Washington, D.C.: Author. Retrieved from http://www.aplu. org/library/the-land-grant-tradition/file

Clemson University. (2014). 2014-2015 undergraduate announcements [Course catalog]. Retrieved from http://www.registrar.clemson.edu/publicat/catalog /2014/2014completeCatalog.pdf

Cornell University, College of Agriculture and Life Sciences [CALS]. (n.d.). The CALS Human Diversity (D) requirement. Retrieved from https://cals.cornell.edu/academics/registrar/ degree-requirements/human-diversity

Finney, C. (2006). Black faces, white spaces: AfricanAmericans and the great outdoors: Final report. Retrieved from http:// nature.berkeley.edu/community forestry/People/Final $\% 20$ Reports/Finney $\% 20$ Final\%20Report.pdf

Grant, G. R., Wood, S. D., \& Wright, W. J. (2012). Black farmers united: The struggle against powers and principalities. Journal of Pan African Studies, 5(1), 3-22. Retrieved from http://www.jpanafrican. com/docs/vol5no1/5.1BlackFarmers.pdf

North Carolina State University. (2014). NC State University undergraduate catalog 2014-2015. Retrieved from http://catalog.ncsu.edu/pdf/2014-2015.pdf

Washington State University. (2014). W ashington State University 2014 catalog. Retrieved from http://www.catalog.wsu.edu/Catalog/PDF Catalo gs/Complete Catalog 2014-15.pdf 